\title{
Changing Climate Related Behaviors: A Review of Social-Scientific Interventions
}

\author{
Anne Marike Lokhorst and Cees van Woerkum \\ Wageningen University \\ The Netherlands
}

\section{Introduction}

Climate change is seen as one of the biggest threats facing our world today, and most people agree that changes are needed to avoid disaster. While technical solutions and environmental policies are definitely promising, they can only be successful when accompanied by changes in human behavior (Stern \& Oskamp, 1987). This chapter addresses such behavioral changes. More specifically, it focuses on social-scientific interventions aimed at changing climate related behaviors. In recent years we have seen an abundance of scientific work dedicated to changing these behaviors and their determinants and contexts. In this chapter we aim to provide the reader with an overview of these endeavors as well as a possible new direction for research.

First, it is important to define what we mean by climate related behaviors. The studies we review in this chapter focus on the broad range of behaviors, but what they have in common is that they impact the natural environment. Within this comprehensive definition, we can distinguish between several types of behaviors (Kazdin, 2009), such as curtailment behaviors (e.g., using less water or saving energy), behavioral choices and decision making about (not) doing something, or doing something differently (e.g., compensating airline travel CO2 emissions, choosing public transport over car), and technology choices (e.g., driving hybrid cars, installing solar panels). Different behaviors come with different costs, both in terms effort and finances. Also, different behaviors are performed in different contexts: some behaviors are performed within the household for example, while others are highly individual. Finally, behaviors differ in terms of the impact they exert on the environment. While all these differences are noteworthy and relevant to take into consideration when studying specific behaviors, in this chapter we choose to include interventions targeting any climate related behavior. Our focus thereby is on the interventions and how they are designed to affect behavior.

In general, we can identify two ways in which researchers have tried to change climate related behaviors. One is through the conventional path of persuasion: by giving people information and raising awareness on the problem and its consequences, researchers aim to change people's attitudes towards climate issues. Attitudes are defined as individuals' evaluations of certain concepts: it is a personal evaluation of whether a given concept is positive or negative (Ajzen \& Fishbein, 1980). As attitude is in most circumstances a strong predictor of behavior (Ajzen, 1991) this can be considered a successful route to behavior change. Examples of such interventions include educational programs, mass-media 
campaigns, informing people and administering feedback. Providing people with (monetary) incentives for the desired behavior is a viable strategy as well. What these strategies have in common is that they treat the individual as a rational decision maker who carefully evaluates the advantages and disadvantages of a certain behavior and chooses to do that what is deemed most appropriate or attractive. By making the 'wanted' behavior appear more important or attractive, behavior change is promoted.

A second class of interventions recognizes that individuals are not always capable or motivated to engage in such processes of extensive decision making. Instead, people are often distracted, indifferent, or unaware of their motivations for specific decisions. Also, a lot of environmental behaviors are habitual: they are part of an everyday routine that is carried out without much conscious thinking. This second class of interventions also recognizes that humans are in essence social beings who are - even without being aware of it- heavily influenced by what others in direct surroundings are doing. In the next two paragraphs, we will give a (non-comprehensive) overview of interventions from both these perspectives. While we do not argue that both types are mutually exclusive and there is never any overlap between them, we do believe that contrasting them presents the reader with a nice state of the art review of social scientific work in the climate domain. We follow up with a possible new perspective on changing climate related behaviors: the action perspective. This perspective addresses people's conversations about climate change and their own climate behaviors as a focal issue. Talking to others can operate as a form of selfpersuasion and this can be a powerful tool for change. We will explore this new perspective and discuss how it might open up new direction for research in this area. Finally, we discuss the implications of our review and highlight the research agenda.

\section{Interventions aimed at changing climate related behaviors: The classic approach}

The classic approach to behavior change is aimed at influencing beliefs, knowledge and preferences relevant to the behavior at stake. The general idea is that once people change their minds, as a consequence they change their behavior. Examples of intervention techniques rooted in this approach include the dissemination of information, giving people feedback and providing them with incentives.

\subsection{Education and information}

A common approach to promote climate friendly behavior is giving people information about climate issues and behavioral responses to mitigate these. Such information can raise awareness of the seriousness of the climate crisis and increase knowledge about possible solutions (Abrahamse, Steg, Vlek, \& Rothengatter, 2005). Information can create or alter beliefs about climate related behaviors and with that, change attitude people hold towards those behaviors. Information can be aimed at large groups of people or at individuals. In the former case, we speak of mass media campaigns. A study by Staats, Wit, and Midden (1996) examined the effectiveness of such a campaign concerning the greenhouse gas effect. It was found that while the campaign did lead to a slight increase in knowledge, intention to change behavior was only affected for those who were already concerned with the environment before having been exposed to the campaign. The effects thus appear to be limited at best. Others (Bamberg \& Moser, 2007; Nickerson, 2003) have also concluded that knowledge of environmental issues is not very closely related to behavior. While it is 
important that people have at least some knowledge of climate issues and possible solutions, it is usually best to combine information with other interventions (Gardner and Stern, 2002).

\subsection{Feedback}

While mass media and other informational campaigns are usually aimed at bringing out general information, feedback programs tend to be more tailored to the individual (Staats, Harland and Wilke, 2004). Administering feedback entails providing people with information about their current climate related behavior and its consequences. A distinction is made between feedback on the individual and on the group level. The latter is also described as a type of comparative feedback as it provides the opportunity to compare one's behavior with that of others. This way feedback can be successful in changing behavior because it possibly makes salient a social norm in favor of the behavior at stake (Abrahamse, Steg, Vlek, \& Rothengatter, 2007). A review of intervention studies aimed at household energy conservation found that feedback was a successful intervention, especially when given frequently (Abrahamse et al., 2007). Other studies on energy saving also revealed feedback to be powerful tool for change (Nickerson, 2003); from these studies some general recommendations for effective feedback can be gathered. First, it is important that feedback is presented in a way that the individual can understand it. While this may seem trivial, it really isn't: not everyone knows what a kilowatt or liter is, depending both on general knowledge and place of birth. Also, it is vital that feedback is administered immediately after the behavior occurs (Geller, 2002) and that the feedback is connected to a tangible behavior - e.g., an increase in energy use due to more air conditioning. This way, the feedback makes clear what can or should be changed. Many devices that are currently used for feedback purposes - such as gas meters - unfortunately do not provide such a clear connection between behavior and its outcomes. We believe that herein lies an important technological challenge.

\subsection{Incentives}

Another fairly common approach for behavior change, especially for policymakers, is the use of incentives: through subsidy plans or tax rebates climate friendly behaviors, such as buying hybrid cars, installing sonar panels or energy-efficient light bulbs are made more attractive for individuals. Another example is the subsidy schemes to promote agricultural conservation practices that most European countries have set up as part of the EU Common Agricultural policy (CAP). Reinforcing wanted behavior by financially rewarding it seems pretty straightforward and prone to success - when a particular behavior yields a reward, it becomes more attractive, and thus positive attitudes toward the behavior should increase. Yet, caution is advised, as such reinforces may backfire. The mechanism through which such backfiring might occur is the so-called 'crowding out' effect (Frey, 1997). To explain this phenomenon it is important to distinguish between intrinsic and extrinsic motivation. When behavior is intrinsically motivated, it is performed not because of an external reward or a wanted outcome, but purely for the sake of the behavior itself. If we see motivation as a continuum, at the other extreme end we find extrinsic motivation which is based solely on rewards that the behavior will yield. Needless to say that in reality, behavior is usually not completely intrinsically or extrinsically motivated, but rather falls somewhere in between. What happens when behavior that is intrinsically motivated gets rewarded? Research has 
shown that rewarding a behavior can cause a decline in intrinsic motivation for this behavior. People start attributing their motivation to the reward and thus their motivation becomes dependent on that reward. If the reward gets taken away (which happens often during changes in political climate), people are no longer motivated. Therefore, financially rewarding climate related behaviors creates a dependency that is self-sustaining, costly, and thus vulnerable.

\subsection{The classic approach: Summary and conclusions}

We reviewed three commonly used intervention techniques that are rooted in the classic approach to behavior change: information, feedback and incentives. All three interventions are based on changing attitudes towards climate related behaviors. Attitudes consist of beliefs about outcomes of behaviors (e.g., 'Using public transport decreases my carbon footprint') and the value people attach to these outcomes (e.g., 'I find it important that my carbon footprint does not grow'). Giving people information and feedback may create or alter beliefs about those behaviors, while the provision of incentives might affect the value component of the attitude.

Such interventions are warranted on the attitude-behavior relationship and as such, they assume that conscious, rational ideas about behavioral consequences and their importance underlie human decision making. Recent studies, however, have shown us that decision making is often characterized by bounded rationality and prone to be influenced by many context variables, often times outside awareness. In the next section, we will review interventions based on such less rational considerations. Specifically, we will focus on social influence and commitment making, priming, emotions and the self-concept.

\section{Interventions aimed at changing climate related behaviors: The unobtrusive approach}

\subsection{Social influence: Social norms and commitment making}

People are strongly influenced by their social environment, and their feelings, thoughts and behavior are usually very much affected by what others do and say. This phenomenon is referred to as social influence, and it comes in many forms. The two that will be discussed here are social norms and commitment making. Both interventions are drawn from social influence and have shown to influence a plethora of climate related behaviors.

\subsubsection{Social norms}

One of the most successful lines of research in the area of climate and behavioral change has definitely been (an still is) that towards the use of social norms. But what are they? Social norms are behavioral rules of a group, as perceived by the individual. As such they describe what is seen as common or appropriate, and individual group members use this information as a guide for their own behavior. Note that the term 'group' is used loosely and can refer to such compositions as cultures, families, peer groups, and even dyads. Descriptive social norms refer to what an individual thinks others do in a particular situation, while injunctive social norms refer to what an individual thinks others approve or disapprove of (Cialdini, Reno \& Kallgren, 1990). For instance, seeing lots of other people recycling provides a strong descriptive norm: it informs us of the behavior of others. Hearing people talk about how recycling is important as it benefits our environment provides an injunctive norm as it informs us of other people's approval of this type of behavior. There is ample evidence for 
social norms influencing a wide range of climate related behaviors. A recent study by Göckeritz et al. (2010) showed that beliefs about conservation behaviors of others (descriptive normative beliefs) were significantly associated with people's own conservation behavior. This relation was even stronger for those who also held strong beliefs about others approval of conservation (injunctive normative beliefs).

In another study on the effect of norms on climate related behavior, a team of researchers looked into the reuse of towels by hotel guests. Nowadays, as part of programs on conserving resources and saving energies, hotels often ask their guests to consider using their towels for more than one day. One often finds these requests on signs placed in the bathrooms. These researchers (Goldstein, Cialdini, \& Griskevicius, 2008) examined whether a social norms approach would lead to an increase in towel recycling. In half of the hotel rooms, the standard 'please help save the environment by recycling your towel' message was replaced by a message stating that the majority of guests at this hotel recycled their towels. Results showed that guests who had been presented with the latter message were $26 \%$ more likely to recycle their towel, indicating once again the strong effect that behavior of others has on us.

\subsubsection{Commitment making}

Another behavioral change strategy rooted in the concept of social influence is commitment making, whereby an individual is asked to make a pledge or commitment to change their behavior. Usually such commitments are made in a group of peers. Several studies have shown a positive effect of commitment making on behavior change. For instance, Burn and Oskamp (1986) carried out a commitment intervention that was aimed at household recycling. Participants in the commitment conditions were approached by a Boy Scout who asked them to sign a pledge card. If they signed the pledge, the scout handed them a sticker to post in their home to remind them to recycle. Results of this study showed a significant difference between the commitment condition and the control group in frequency of recycling.

Cobern, Porter, Leeming and Dwyer (1995) conducted a study in which they examined the effects of two types of commitment on residential grass recycling. Participants were asked to commit to grass recycling and, in a second condition, were also asked to talk to their neighbors about their recycling. The commitment to the target behavior was written, but the commitment to talk to their neighbors was done verbally. Both types of commitment were made with the experimenters present. Results showed that only participants who made both types of commitment significantly changed their behavior.

Another study (Lokhorst, van Dijk, Staats, van Dijk \& de Snoo, 2010) looked at the effects of commitment making on farmers' nature conservation efforts. Here, the commitment making was combined with feedback on current conservation and tailored information on how to improve. Results showed that one year after having committed to change, farmers showed an increased intention to conserve, more time spent on conservation and an expansion in area of (semi-)natural habitat on their farms.

Both the social norms and the commitment making approach this seem viable strategies to change climate related behaviors. Still, the nature of their effectiveness remains a topic of debate. Commitment making is often assumed to rely on the presence of peers, creating some sort of social pressure to adhere to one's commitment. Yet other studies show that people adhere to commitments even in the absence of others (Kerr, Garst, Lewandowski, \& Harris, 1997), rendering the social pressure explanation less likely. While it may be 
interesting on a theoretical level to pit these explanations against each other, in real life situations they probably operate in tandem. What may start as a feeling of being pressured into something by the soial environment may eventually become internalized. As for social norms, one of the current questions in research is whether their effects are automatic, outside of conscious processing, or whether they require some level of cognitive elaboration. Recent studies indicate that while normative social influence can occur automatically (Nolan, Schultz, Cialdini, Graskevicius and Goldstein, 2008), certain context variables (such as for instance personal involvement) can enhance elaboration (Göckeritz et al., 2010). Again, this is in line with our notion that in real life settings, multiple factors work together in influencing behavior.

\subsection{Use of heuristics and priming}

While discussion about the automaticity of normative social influence remains, recently there has been an interest in other automatic influencing: that of the use of heuristics and primes. This work is based on the assumption that because climate change is characterized with uncertainty - the topic is too difficult to fully grasp-, people's beliefs about climate change will be based on heuristics and accessible schemas susceptible to primes. Heuristics are rules of thumb; cognitive shortcuts that people use to guide their decisions when risks or probabilities are difficult and uncertain. Examples of such shortcuts are 'the experts know', or 'if the majority says so, it must be true'. Primes are stimuli that activate schemas: associated networks of related concepts to influence perception and behavior. Research by Joireman, Truelove and Duell (2010) shows that not only are beliefs in global warming correlated with outdoor temperature (the higher the temperature, the stronger the belief in climate change) but also that priming people with heat related cognitions increased beliefs in climate change. That is, participants who performed a word search puzzle containing heat related words (such as boil and fry) showed a stronger belief in global warming than participants whose word puzzle contained neutral words. Two important conclusions can be drawn from this research. One, as the researchers themselves point out: when investigating beliefs about climate change, one should be careful in designing the survey and selecting the time and place of measurement, avoiding any context factors that might prime heat-related cognitions and with that affect climate change beliefs. Second, to the extent that beliefs about climate change underlie climate related behavior, this line of research opens up a new wide array of possible intervention techniques based on automatic influencing. One could for instance investigate what other concept people associate with climate change and how they can be used in real life interventions.

\subsection{Self-concept and labeling}

When psychologists speak of the self-concept, they refer to an individuals' perception of the self; in other words, how a person sees him- or herself. The self-concept is thus a bundle of self-assessments, such as for instance 'I am attractive', 'I am bad at algebra', and 'I am someone who cares about the environment'. The latter example suggests that these aspects of the self-concepts may underlie climate related behavior and can therefore be targeted in interventions. It has been suggested for instance that the making of commitments makes salient or even alters certain aspects of the self-concept that are relevant to environmental decision making, and that this change mediates the effect of commitment making on behavior (Lokhorst, Werner, Staats, van Dijk, and Gale, in press). 
Based on this connection between the self-concept and behavior is a technique named 'labeling', where one assigns a trait, belief, or any other label, to a person and then makes a request that is consistent with this label. Research shows that people are likely to follow up on these requests. Pallak and Cummings (1976) conducted a study aimed at energy conservation. They approached participants with the request to start saving energy. One half of the participants were told that their names would appear in the local newspaper as "public-spirited, fuel-conserving citizens". After a month the homeowners in this sample saved significantly more energy than the control group. Then, the participants were told that it would not be possible to publicize their names in the paper after all. For a period of 12 months the researchers measured the energy usage of these families. It appeared that during these months they had actually conserved more fuel than during the time they believed their names would be printed in the newspaper (Pallak \& Cummings, 1976).

Especially noteworthy in this study is that participants in the public commitment condition were told that their names would be listed as "public-spirited, fuel-conserving citizens". Labeling them as such seems to refer directly to their self-concepts as "the kind of people who do such things", and thus made it more likely that they saved energy.

Another way in which the self-concept can be relevant to our topic is illuminated by research on self-affirmation and involvement with climate change and willingness to recycle (Sparks, Jessop, Chapman \& Holmes, 2010). In their first study, these researchers were able to show that people who were self-affirmed, that is, who were manipulated into thinking positively about themselves, showed lower levels of denial of climate change, and greater perceptions of personal involvement. How does this work? In general, denial is seen as a defense mechanism: when people are threatened (for instance by climate change), one way to cope with this threat is denying the problem. Self-affirmation theory (Steele, 1988) predicts that self-affirmations boost the self-concept, making defensive reactions less necessary, and leading people to more open to threatening information. This is indeed what these researchers found. Moreover, in their second study, they managed to show that the effect of self-affirmation extended to recycling behavior: participants who were self-affirmed showed greater intentions to recycle than those who were not self-affirmed (Sparks et al., 2010).

\subsection{Emotions}

An opportunity that as of today has not been given a lot of attention in social scientific research is the idea that emotions might also underlie climate related decision making and behavior. It has been shown for instance that having emotional ties with nature is of significant influence to environmental decision making (Kals, Schumacher and Montada, 1998). More direct evidence for emotions as a successful behavior change technique comes from work by Ferguson and Branscombe in 2010. In two studies they were able to show that experiencing collective guilt concerning greenhouse gas emissions leads people to express greater willingness to conserve energy and to pay 'green' taxes. While guilt of course is a negative emotion, it might very well be that positive emotions (such as for instance pride or happiness) affect climate related behaviors as well. We believe that herein lies an interesting new approach for climate change researchers and communication professionals. Finding out which emotions might affect climate related behaviors and how will provide new input for campaigns aimed at bringing about behavioral change.

\subsection{Breaking the habit}

Many of the climate related behaviors we perform are habitual; they are not the result of conscious reasoning, weighing in the pros and cons of our options, but simply behaviors we 
have grown accustomed to and would rather not part with. Such behaviors are usually performed repetitively, in a stable context. Travel mode choice for instance, has shown to be an extremely habitual behavior (Verplanken, Walker, Davis, \& Jurasek, 2008). One consequence of behavior being habitual is that people are not very open to acquiring information about alternatives and options for behavior change (Verplanken, Aarts, \& Van Knippenberg, 1997). Therefore, classic approaches relying on dispersing information are not likely to be effective. But what can be done to break habits?

Habitual behaviors are cued by recurring stimuli in a stable context (Wood, Tam, \& Guerrero Witt, 2005; Wood \& Neal, 2007). Therefore, changing this context - and thus the recurring stimuli- should strongly impact these behaviors. This idea is referred to as the discontinuity hypothesis (Verplanken, Walker, Davis, \& Jurasek, 2008). Indeed, these authors have shown that a change in context - in their study, people moving house impacted travel mode choice, but only for those who were already environmentally concerned. The researchers interpreted this as the context change creating a window of opportunity for people to break their habits and let their environmental values influence their behavior. This goes to show that when we try to change behavior we should not only focus on the psychological determinants bust also on possibilities for change in the context in which behavior takes place.

\subsection{The unobtrusive approach: Summary and conclusions}

We have reviewed several studies that make use of social psychological insights in behavior, its determinants and the contexts in which it is performed. We have seen that concepts such as norms, priming, emotions and the self-concept play a role in climate related behavior and that they can be targeted by interventions. Moving away from the classic approach that is rooted in the attitude-behavior relationship gives us the opportunity to acknowledge that behavior is multi-faceted and context-dependent. It also opens up a new and wired array of different behavior change techniques based on more recent insights from social psychology. Before we move to our general discussion we would like to present the reader with a new perspective on changing climate related behaviors: the action perspective.

\section{The action perspective}

As we saw earlier in this chapter knowledge about environmental issues is not always closely related to behavior. Many people are aware of the necessity to change their routines because of the climate problem, and are possibly also willing to change, but at the same time utterly incapable of doing so. The reasons are mainly that climate related behavior is not a clear cut separate fraction of human activity, but that it is embedded in social practices and routines, such as daily commuting or living in a spacious and comfortable house with a lot of helpful devices. Changing these practices mostly has social consequences. For instance, travelling by public transport to your office often means spending less time with relatives at home. Opting for the 'better' alternative urges for discursive action to justify the new behavior in the eyes of others. If the choice is a collective one, such as for instance lowering the thermostat in the living room, people might actually have to try and get their family members' permission.

The action perspective is directed at the very process of making change happen in a given social context (Bouwman and Van Woerkum, 2008). It looks at the barriers at the level of everyday life but also at how some people succeed to overcome these barriers. These people 
can act as role models, not only because others can identify with them, but because they can show how things can get done. These successful changers can be invited to share their experiences on website fora. As another option, their experiences can be played out in soaps, which may be broadcasted on TV for a large audience. The objective is that basically motivated individuals learn to implement their good intentions in their own social context. In their work on so-called guided group discussions, Werner, Sansone, and Brown (2008) also stressed that researchers and policy makers recognize that new behaviors are always embedded in social larger social, environmental, economic, and policy contexts. They propose letting people discuss these new behaviors with others (in guided group discussions) as a means of offering a supportive social setting.

\section{Discussion}

After having reviewed several strategies aimed at bringing about behavioral change, what can be concluded concerning their effectiveness? Is one type of strategy preferred over the other? Can they be combined? How should professionals select which strategies to employ? We propose that, in accordance with the action perspective, each behavior change program starts with an extensive study of nature of behavior as well as the context in which it takes place. What can be said about the behavior in question? To what extent is it automatic, habitual, or subject to routines? Are other people involved, or affected by the outcomes? Is the behavior difficult or costly to perform, does it require a high level of specific knowledge? Only when through such careful analysis the specific determinants of the behavior in question can be determined, one can make an informed decision as to what intervention strategy to use to alter the behavior.

For instance, when a behavior is highly habitual, presenting people with information concerning alternative options is not likely to bring about change. Instead, the context in which the behavior takes place should be examined and checked for possibilities: can a window of opportunity be created in which a change in context offers leeway for people to break their habit? Or, when a specific behavior mostly takes places in a strong social environment, what are the dominant normative influences? Can a message be construed that informs people about that behavior of others so that they will change theirs accordingly? Or, when we know that a specific behavior is largely based on heuristic processing, we might look for automatic associations that people use in their decision making. What matter is that interventions should be chosen based on the nature and the context of the behavior that is targeted.

At the same time, it should be recognized that behavior is always multi-faceted and never determined by one single factor. Likewise, when applying social scientific knowledge to natural settings, one should never assume that one specific strategy will do the trick instead, a combination of interventions is to be preferred. Numerous studies have shown that usually, combined interventions are most effective in producing durable behavior change (see, for example, DeLeon \& Fuqua, 1995; Lokhorst et al., 2010; Staats et al., 2004). So, a few interventions that are likely to yield result should be chosen and combined in a multilevel intervention.

The next stage of any successful intervention program is one that is often overlooked by social scientists: the implementation. Who will be administering the intervention? What are people's attitudes towards or relations with these institutes, experts or authorities? What media will be used? How will the target group be invited to participate in the program? 
Does participation come with a cost, and if so, what cost? Where do people turn to when they have questions? All these more practical aspects of behavior change programs must be taken into consideration when developing an intervention. Just as selecting the right technique, they are key to the success of the program.

Another sometimes forgotten but nevertheless vital aspect of change programs is the follow up. When can behavior change be expected and measured? What is considered long term behavioral change, and how long can you monitor participants? Many intervention programs claim they lead to long term durable change yet fail to check up on participants after the program has ended. Of course, continued monitoring is difficult and costly, but at the same time it is tremendously valuable if we can see how and for how long behavior change can occur.

\section{Conclusion}

Countering the adverse consequences of climate change relies heavily on changes in human behavior. In order to successfully change behavior, we need to understand its nature as well as the context in which it is performed. This is where the social sciences come into play. We strongly believe that collaboration between the natural and the social sciences is a vital precondition for creating successful behavioral change programs. Hopefully, this chapter has provided an overview of the broad range of possible interventions derived from social scientific research.

\section{References}

Abrahamse, W., Steg, L., Vlek, C., \& Rothengatter, T. (2007). The effect of tailored information, goal setting, and tailored feedback on household energy use, energyrelated behaviors, and behavioral antecedents. Journal of Environmental Psychology, 27, 265-276.

Abrahamse, W., Steg, L., Vlek, C., \& Rothengatter, T. (2005). A review of intervention studies aimed at household energy conservation. Journal of Environmental Psychology, 25, 273-291.

Ajzen, I. (1991). The theory of planned behavior. Organizational Behavior and Human Decision Processes, 50, 179 - 211.

Bouwman, L., \& van Woerkum, C. (2008). Placing healthful eating in the everyday context: towards an Action Approach of gene-based personalised nutrition advice. In D. Castle \& N. Ries (Eds.), Nutrition and Genomics; Issues of Ethics, Regulation and Communication. San Diego: Elsevier.

Burn, S. M., \& Oskamp, S. (1986). Increasing community recycling with persuasive communication and public commitment. Journal of Applied Social Psychology, 16(1), 29-41.

Cialdini, R. B., Reno, R. R., \& Kallgren, C. A. (1990). A focus theory of normative conduct: Recycling the concept of norms to reduce littering in public places. Journal of Persocality and Social Psychology, 58, 1015-1026.

Cobern, M. K., Porter, B. E., Leeming, F. C., \& Dwyer, W. O. (1995). The effect of commitment on adoption and diffusion of grass cycling. Environment and Behavior, 27(2), 213-232. 
DeLeon, I. G., \& Fuqua, R. W. (1995). The effects of public commitment and group feedback on curbside recycling. Environment and Behavior, 27, 233-250.

Frey, B.S. (1997). On the relationship between intrinsic and extrinsic work motivation. International Journal of Industrial Organization, 15, 427-439.

Gardner, G. T., \& Stern, P.C. (2002). Environmental problems and human behavior. Boston, MA: Pearson Custom Publishing. 2nd Ed.

Geller, E.S. (2002). The challenge of increasing proenvironment behavior. In R. G. Bechtel \& A. Churchman (Eds.) Handbook of Environmental Psychology (pp. 525-540). New York: Wiley.

Göckeritz, S., Schultz, P. W., Rendón, T., Cialdini, R. B., Goldstein, N., \& Griskevicius, V. (2010). Descriptive norms and conservation behavior: The moderating role of personal involvement and injunctive normative beliefs. European Journal of Social Psychology, 40, 514-523.

Goldstein, N., Cialdini, R. B., \& Griskevicius, V. (2008). A room with a viewpoint: Using social norms to motivate environmental conservation in hotel rooms. Journal o Consumer Research, 35, 472-482.

Kals, E., Schumacher, D., \& Montada, L. (1998). Experience with nature, emotional ties to nature, and ecological responsibility as determinants of nature protective behavior. Zeitschrift fur Sozialpsychologie, 29, 5-19.

Kazdin, A. E. (2009). Psychlogical science's contribution to a sustainable environment. American Psychologist, 64, 339-356.

Kerr, N. L., Garst, J., Lewandowski, D. A., \& Harris, S. E. (1997). That still, small voice: Commitment to cooperate as an internalized vs. a social norm. Personality and Social Psychology Bulletin, 23, 1300-1311.

Lokhorst, A. M., Werner, C.M., Staats, H., Van Dijk, E., \& Gale, J. (in press). Commitment and Behavior Change: A Meta-analysis and Critical Review of Commitment Making Strategies in Environmental Research. Environment \& Behavior.

Lokhorst, A.M., Van Dijk, J., Staats, H., Van Dijk, E., \& De Snoo, G. (2010). Using tailored information and public commitment to improve the environmental quality of farm lands: An example from the Netherlands. Human Ecology, 38, 113-122.

Nickerson, R. S. (2003). Psychology and environmental change. Mahwah, NJ: Erlbaum.

Nolan, J. Schultz, P. W., Cialdini, R. B., Griskevicius, V., \& Goldstein, N. (2008). Normative social influence is underdetected. Personality and Social Psychology Bulletin, 34, 913923.

Pallak, M., \& Cummings, N. (1976). Commitment and voluntary energy conservation. Personality and Social Psychology Bulletin, 2, 27-31.

Sparks, P., Jessop, D. C., Chapman, J., \& Holmes, K. (2010). Pro-environmental actions, climate change, and defensiveness: Do self-affirmations make a difference to people's motives and beliefs about making a difference? British Journal of Social Psychology, 49, 553-568.

Staats, H., Harland, P, \& Wilke, H. A. M. (2004). Effecting durable change: A team approach to improve environmental behavior in the household. Environment and Behavior, 36, 341-367.

Steele, C. M. (1988). The psychology of self-affirmation: Sustaining the integrity of the self. In L. Berkowitz (Ed.), Advances in experimental social psychology (Vol. 21, pp. 261302). San Diego, CA: Academic Press. 
Stern, P. C., \& Oskamp, S. (1987). Managing scarce environmental resources. In D. Stokols and I. Altman (Eds.), Handbook of Environmental Psychology, ( pp. 1043-1088). New York: Wiley.

Verplanken, B., Walker, I., Davis, A., \& Jurasek, M. (2008). Context change and travel mode choice: Combining the habit discontinuity and self-activation hypotheses. Journal of Environmental Psychology, 9, 15-26.

Verplanken, B., Aarts, H., \& van Knippenberg, A. (1997). Habit, information acquisition, and the process of making travel mode choices. European Journal of Social Psychology, 27, 539-560.

Wood, W., \& Neal, D. T. (2007). A new look at the habit-goal interface. Psychological Review, 114, 843-863.

Wood, W., Tam, L., \& Guerrero Witt, M. (2005). Changing circumstances,disrupting habits. Journal of Personality and Social Psychology, 88, 918-933. 


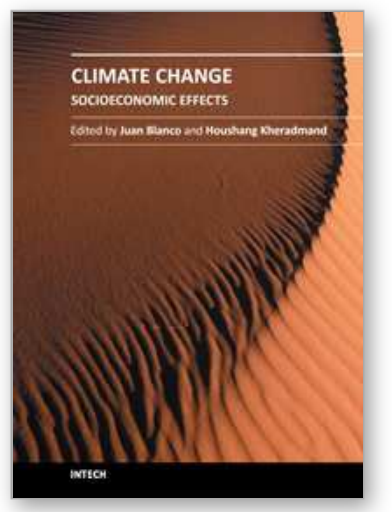

\author{
Climate Change - Socioeconomic Effects \\ Edited by Dr Houshan Kheradmand
}

ISBN 978-953-307-411-5

Hard cover, 454 pages

Publisher InTech

Published online 09, September, 2011

Published in print edition September, 2011

This book shows some of the socio-economic impacts of climate change according to different estimates of the current or estimated global warming. A series of scientific and experimental research projects explore the impacts of climate change and browse the techniques to evaluate the related impacts. These 23 chapters provide a good overview of the different changes impacts that already have been detected in several regions of the world. They are part of an introduction to the researches being done around the globe in connection with this topic. However, climate change is not just an academic issue important only to scientists and environmentalists; it also has direct implications on various ecosystems and technologies.

\title{
How to reference
}

In order to correctly reference this scholarly work, feel free to copy and paste the following:

Anne Marike Lokhorst and Cees van Woerkum (2011). Changing Climate Related Behaviors: A Review of Social-Scientific Interventions, Climate Change - Socioeconomic Effects, Dr Houshan Kheradmand (Ed.), ISBN: 978-953-307-411-5, InTech, Available from: http://www.intechopen.com/books/climate-change-socioeconomiceffects/changing-climate-related-behaviors-a-review-of-social-scientific-interventions

\section{INTECH}

open science | open minds

\section{InTech Europe}

University Campus STeP Ri

Slavka Krautzeka 83/A

51000 Rijeka, Croatia

Phone: +385 (51) 770447

Fax: +385 (51) 686166

www.intechopen.com

\section{InTech China}

Unit 405, Office Block, Hotel Equatorial Shanghai

No.65, Yan An Road (West), Shanghai, 200040, China 中国上海市延安西路65号上海国际贵都大饭店办公楼 405 单元

Phone: $+86-21-62489820$

Fax: +86-21-62489821 
(C) 2011 The Author(s). Licensee IntechOpen. This chapter is distributed under the terms of the Creative Commons Attribution-NonCommercialShareAlike-3.0 License, which permits use, distribution and reproduction for non-commercial purposes, provided the original is properly cited and derivative works building on this content are distributed under the same license. 